\title{
Feminismo y las técnicas de reproducción asistida
}

FRANCESCA PUIGPELAT MARTI

Catedrática de Filosofía del Derecho, Universidad Autónoma de Barcelona

\section{INTRODUCCIÓN}

Las técnicas de reproducción asistida han sido objeto de debate desde su inicio. Se han situado críticamente frente a ellas no sólo los sectores más conservadores de la sociedad, sino también ciertos sectores progresistas, al percibirlas como un fruto más del amenazante desarrollo científico-tecnológico. Uno de los movimientos sociales emancipatorios más importante desde los años sesenta ha sido el feminista. También desde él se ha tomado posición a favor y en contra de dichas técnicas. Esta diversidad de apreciación no debe extrañamos, pues el movimiento feminista no es un todo monolítico sino que está integrado por una pluralidad de puntos de vista. De ahí que las discrepancias sean frecuentes en tomo a la valoración de determinados temas. Esta pluralidad, sin embargo, es la que ha contribuido, también, a dotarlo de una gran riqueza.

Esta intervención tiene por objeto mostrar, a grandes rasgos, las distintas corrientes dentro del feminismo, exponer las razones por las que 
es comprensible que el feminismo no sea indiferente a las técnicas de reproducción asistida y las diversas posiciones que frente a ellas ha adoptado.

\section{EL FEMINISMO}

Nadie ha puesto en duda que la posición social de las mujeres, en las sociedades que hemos conocido hasta ahora e incluso en las actuales, no es la misma que la de los hombres. Lo que sí se ha cuestionado es que ello fuese injusto para las mujeres pues para muchas personas esta desigualdad social se encuentra justificada por la necesidad de distribuir las tareas sociales de la forma más operativo posible en relación con las características biológicas propias de cada sexo. Desde esta perspectiva la relación existente entre los hombres y las mujeres sería la de la complementariedad. Pero, precisamente, esta idea no es la que comparte el feminismo.

La tesis básica del feminismo es que la relación de las mujeres respecto de los hombres es una relación de subordinación y que debe lucharse para acabar con esta situación injusta para las mujeres.

Lo que ya no es unitario en el seno del movimiento feminista son las explicaciones que se aportan sobre las causas que explican esta situación de discriminación y las medidas que deben llevarse a cabo para acabar con ella. En relación con estas cuestiones, y a riesgo de caer en una cierta simplificación, podemos señalar la existencia dentro del feminismo de cuatro grandes corrientes:

1. El feminismo liberal.

2. El feminismo marxista-socialista.

3. El feminismo radical.

4. El feminismo cultural. 


\subsection{EL FEMINISMO LIBERAL}

Las feministas liberales consideran que la mujer, un ser racional y libre como el hombre, se halla discriminada porque no disfruta de los mismos derechos y oportunidades que los hombres. Aunque los textos legales garantizan formalmente derechos idénticos para ambos sexos, su efectividad en la vida real no está asegurada en el caso de las mujeres. Para esta corriente la situación de discriminación acabará cuando la mujer tenga realmente los mismos derechos y oportunidades que los hombres. En el famoso libro de Friedan, La mística de la feminidad, publicado en 1963, pueden verse reflejadas estas tesis.

\section{L.2. EL FEMINISMO MARXISTA-SOCIALISTA}

El feminismo marxista-socialista concibe la opresión de la mujer como una más de las consecuencias que se derivan de la existencia de la propiedad privada. El modo de producción capitalista, imperante en las sociedades actuales, en la medida en que se asienta sobre la propiedad privada de los medios de producción hereda y refuerza la opresión de la mujer. Las relaciones no igualitarias entre hombres y mujeres sólo acabarán cuando se supere el modo de producción capitalista. En una sociedad en la que los medios de producción estén socializados desaparecerá la explotación clasista y, con ella, la subordinación de la mujer. En la obra de Engels, El origen de la familia, la propiedad privada y el Estado, publicada en 1884, tiene su punto de partida este planteamiento,

Pero en el seno del marxismo crítico de los años setenta y ochenta se discutió ya si la emancipación de la mujer exige algo más que la superación del capitalismo en vista de la situación de las mujeres en las sociedades en las que ya se habían socializado los medios de producción y de la posición subordinada de éstas en las organizaciones de izquierda. Algunas feministas considerarán por ello, que la opresión femenina no puede verse sólo como una derivación de la explotación clasista. Parecerá más adecuado admitir, por la influencia del feminismo radical, 
que en las sociedades capitalistas tiene lugar una doble opresión, la de clase y la de sexo (Uria, Pineda, Oliván, 1985.)

\subsection{EL FEMINISMO RADICAL}

El feminismo radical concibe la subordinación femenina como el producto de una determinada construcción social: el patriarcado. Este concepto se introduce en la obra de Millet, Política sexual, publicado en 1970. La conceptualización del patriarcado como institución destinada a perpetuar la opresión de los hombres sobre las mujeres ha sido diversa dentro del feminismo radical. Pero con él quiere destacarse, sobre todo, que las relaciones entre los sexos están marcadas por las relaciones de poder que los hombres ejercen sobre las mujeres en todas las áreas de la vida y no sólo en el ámbito público y económico. Este poder se articula socialmente en torno a la construcción de género "masculino" y "femenino" y sus correspondientes roles. Los roles de género "masculino" y "femenino" se asientan sobre diferencias biológicas, pero van más allá de ellas. Robert Stoller fue uno de los primeros científicos que estableció la diferencia entre sexo y género. El caso que tuvo como punto de referencia fue el de un niño al que por accidente, al hacerle la circuncisión, le amputaron el pene. Los padres y los médicos consideraron que era mejor que fuese una "mujer" y lo socializaron como tal. Ni el niño, ni las personas que lo rodeaban, desconocedoras de su identidad sexual, tuvieron nunca problemas con la nueva identidad social. Esto le llevó a suponer que lo determinante para la identidad sexual no es el sexo biológico, sino el estar socializado según un determinado rol social (Facio, 1992, p. 58 ss.).

El rol masculino, dotado de superioridad, se articula, a su vez, en torno a unas habilidades, disposiciones y valores que favorecen dicha posición, mientras que el rol femenino, infrasituado, se vincula a unas habilidades, disposiciones y valores que perpetúan su posición de inferioridad. La inteligencia, la fuerza, la independencia, el poder, la acción se consideran inherentes al rol masculino. La emotividad, la vulnerabilidad, la dependencia, el atractivo sexual -preferentemente liga- 
do a la juventud-, la pasividad se consideran propias del rol social femenino. Es fácil entender por qué esta distribución sitúa a las mujeres en una posición de clara desventaja.

Es cierto que desde hace tiempo las mujeres pueden ocupar posiciones sociales que antes sólo estaban atribuidas a los hombres. Pero lo que se olvida es que estas posiciones sociales han estado diseñadas de forma tal que los más adecuados para ocuparlas son siempre los hombres. Ello se debe a que, como señala Mackinnon, pese a que las normas legales se presentan como neutrales al sexo, la primera vez que éste se tuvo en cuenta fue cuando los trabajos se conformaron presuponiendo que quienes iban a desempeñarlos no tenían la responsabilidad del cuidado de los hijos (Mackinnon, 1987, p. 37.)

Que esto es cierto puede comprobarse claramente observando la distinta forma en la que un hombre y una mujer se plantean la constitución de una familia. Una mujer siempre piensa que formar una familia puede ser un obstáculo para su promoción profesional. Ningún hombre ha pensado, hasta ahora, que ello pudiese ser para él un problema. Es más, para él tener familia puede ser, incluso, positivo para acceder a un cargo de responsabilidad. La elección entre familia o carrera profesional es una opción que los hombres no han tenido que plantearse, salvo casos muy extremos. Si las mujeres hubiesen conformado los trabajos sociales quizás no habrían establecido esta incompatibilidad entre trabajo remunerado, embarazo y cuidado de los hijos.

Para este planteamiento la igualdad entre hombres y mujeres no puede consistir simplemente en que las mujeres puedan acceder a los roles diseñados por y para favorecer a los hombres. La igualdad exige que las mujeres tengan igual poder para crear roles sociales definidos por ellas. Lo que cuestionan las feministas radicales es, en palabras de Habermas, que la igualdad entre los sexos pueda llegar a darse en el contexto de una cultura definida y dominada por los hombres y las instituciones sociales existentes que son coherentes con ella (Habermas, Facticidad y validez, 1998, p. 507. 
Entre el feminismo liberal y el feminismo radical podrían establecerse, según Cain, las siguientes diferencias:

- El feminismo liberal otorga preferencia al sujeto individual (ya sea hombre o mujer); el radical visualiza a la mujer como una clase de sujetos, una clase dominada por otra (los hombres).

- Las liberales en sus análisis tienden a resaltar las similitudes entre los hombres y las mujeres; las radicales, las diferencias, aunque advirtiendo expresamente que dichas diferencias han sido construidas socialmente para situar a las mujeres en una posición de subordinación (Lloyd/Freeman, 1994, p. 1106).

- Las liberales no cuestionan el marco político, económico y social existente, las radicales sí.

\subsection{EL FEMINISMO CULTURAL}

A mediados de los años setenta empieza a utilizarse la expresión "Feminismo cultural". Bajo esta denominación cabe situar aquellos planteamientos que enfatizan las diferencias existentes entre las mujeres y los hombres. Pero esta "diferencia" de las mujeres, que se manifiesta en una cultura propia, distinta de la masculina, no es algo que deba desaparecer, por ser el resultado de la dominación masculina, sino algo que debe ser preservado. Y debe serlo, no sólo porque de otro modo parecería que el modelo al que han de adaptarse las mujeres es el masculino, sino también porque los "valores femeninos" son en sí mismo valiosos y han de ser defendidos.

La contraposición y, para algunos, superioridad de los valores "femeninos" frente a los "masculinos" se consolidó a partir de la publicación en 1982 de la obra de Carol Gilligan, Una voz diferente. En este libro la autora, psicóloga, critica las tesis de Kohlberg sobre las diversas etapas en el desenvolvimiento de la conciencia moral. El desarrollo de la conciencia moral culmina, según este autor, cuando el agente es capaz de pensar los problemas morales desde la perspectiva de principios universales de justicia asumidos de forma reflexiva (Kohlberg, 1984, p. 409 
ss.). Gilligan sostiene, sin embargo, que no hay una única secuencia de etapas en la maduración moral del ser humano sino que hay dos formas distintas de entender la moral: la femenina y la masculina. Lo peculiar de la moral femenina es que las mujeres se sienten obligadas a atender y aliviar las dificultades, mientras que los hombres, a respetar los derechos de los demás y de esta forma garantizar el derecho a la vida y a la autorrealización (Gillígan, 1985, p. 58ss.).

Así mientras los hombres se plantean los problemas éticos desde la perspectiva de los derechos y la justicia, las mujeres lo hacen desde la responsabilidad y el cuidado de los demás. Una concepción moral orientada a las tareas de cuidado vincula el desarrollo moral a la comprensión de las responsabilidades y las relaciones. Las mujeres se explican a sí mismas, básicamente, en su conexión con otras personas y no como alguien separado de los demás. Para las mujeres el problema moral surge cuando hay distintas responsabilidades en conflicto y no cuando entran en competencia distintos derechos. Para resolver esta clase de conflicto es necesario operar con una forma de pensar que sea contextual y narrativa, y no formal y abstracta como es la propia de la ética de la justicia.

La tesis de Gilligan ha sido objeto de diversas críticas. Una de ellas ha sido que, aunque las mujeres piensen más en términos de responsabilidades que de derechos, no puede desconocerse que si las mujeres creen que tienen el deber de ayudar es porque consideran que los que han de ser ayudados tienen derecho a ello. Pero es aquí, precisamente, donde cabe establecer la diferencia más significativa entre los dos planteamientos. Para las mujeres el deber de ayudar viene determinado por el dolor que alguien siente subjetivamente, sea éste justo o injusto. Los hombres, sin embargo, suelen considerar inmoral sólo lo que es injusto, dejando de lado el daño subjetivo (Harding, 1982, p. 237s.). Por ejemplo, si una persona rica, pero generosa, dilapida voluntariamente su fortuna y esto le provoca sufrimiento, desde la ética de la justicia no habría el deber de ayudarla, desde la del cuidado sí. 
En relación a esta diferencia cabría preguntarse: a) si la ética del cuidado no conlleva consecuencias socialmente peligrosas, incluso más para las propias mujeres; y b) si hay alguna razón que condicione su existencia y necesidad de permanencia.

Los defensores de la ética de la justicia consideran que otorgar más peso al daño subjetivo que a la injusticia objetiva puede tener consecuencias sociales muy negativas. Si todo el mundo confía en que cuando se halle en una situación que le provoque dolor, sea cual sea su causa, los otros están obligados a ayudarle esto fomentará la irresponsabilidad general sobre los intereses propios. Tampoco parece justo obligar a las personas que cuidan responsablemente de sus intereses que se hagan cargo de las personas que no asumen sus propias responsabilidades. Además, si desvinculamos el deber de actuar de expectativas justas sería imposible acabar con las situaciones de privilegio. Como ha señalado Kymlicka los opresores sufrirán mucho cuando pierdan sus privilegios, mientras que los oprimidos, al estar socializados en esta situación, no suelen sentir como un daño su opresión. En esta situación estarían las mujeres. Por ello, desde la ética de la justicia se insiste en la bondad de su perspectiva, señalando que las obligaciones morales han de estar fijadas por reglas que las concreten, sin tener en cuenta las valoraciones de los deseos individuales que se manifiestan en contextos concretos. Las responsabilidades deben estar prescritas por reglas y hay que admitir que algunos daños subjetivos no pueden ser fuente de exigencias morales. Los teóricos de la ética del cuidado contraargumentan diciendo que esta exclusión sólo puede defenderse si se cree que las personas sólo tienen relaciones con sujetos adultos, sanos y mentalmente capaces (Kymilicka, 1995, p. 301 ss.).

b) El que en la sociedad deban llevarse a cabo tareas de cuidado socialmente necesarias es lo que condiciona la existencia y permanencia de la ética del cuidado. Precisamente, el que ésta sea patrimonio de las mujeres tiene su razón de ser en que esta ética es más apropiada para satisfacer las necesidades de los sujetos a los que no puede exigírselas 
reciprocidad. Los niños, los enfermos, los ancianos y los incapaces tienen necesidades, de las cuales no son responsables, y que han de serles satisfechas aunque ellos no estén en situación de corresponder. En la medida en que la sociedad ha adjudicado a las mujeres ocuparse de los niños, los viejos y los enfermos, y a tener una posición subordinada en las relaciones con los adultos autónomos, es comprensible que la ética femenina se articule en torno a la idea de que el deber puede nacer del dolor que siente otra persona. Dolor que se, determina de forma subjetiva y no de forma objetiva. La ética de la justicia, basada en derechos y reglas, podría ser, en todo caso, sólo válida para configurar las relaciones entre sujetos adultos y autosuficientes.

La construcción social del rol femenino articulado básicamente en torno a la maternidad y las tareas de cuidado permite, también, dar razón de algunas particularidades que se consideran específicamente femeninas: el atractivo sexual, la disposición al sacrificio, la dependencia y la intuición. Reproducción y atractivo sexual hasta ahora no han sido posibles de escindir: si una mujer no atraía sexualmente a un hombre, difícilmente podía tener hijos. La disposición al sacrificio también es necesaria en la medida en que tener hijos ha significado durante muchos siglos un riesgo para la propia vida de la mujer. La dependencia es inherente al embarazo y a las tareas de cuidado puesto que las necesidades las determina el que es cuidado y no el cuidador. La intuición es fundamental porque las necesidades de los niños, sobre todo en los primeros años de vida, así como las de las personas enfermas, mayores o incapaces sólo pueden captarse intuitivamente.

Que la ética del cuidado sea funcional a las tareas asignadas a las mujeres no excluye que podamos planteamos como un problema de justicia esta distribución de las tareas de cuidado. ¿Por qué ha de aceptarse que la sociedad considere que las tareas de cuidado de los demás sólo formen parte del plan de vida de las mujeres? Una teoría política no sexista ha de incorporar como objeto central de discusión cómo deben distribuirse las tareas de cuidado socialmente necesarias y diseñar meca- 
nismos institucionales para que éstas sean efectivamente realizadas tanto por las mujeres como por los hombres.

\section{EL FEMINISMO ANTE LAS TECNICAS DE REPRODUCCIÓN ASISTIDA}

La justificación última de por qué el rol femenino tradicional se ha articulado en torno a las tareas de cuidado de los demás se hace descansar en el hecho biológico de la maternidad. Es por ello que las diferentes corrientes dentro del feminismo reconocen la centralidad de la maternidad en la vida de las mujeres, aunque la valoren de forma distinta (Chorodow, 1978, p. 169). Para las feministas radicales es un efecto de la cultura patriarcal; para las culturales, una expresión genuina de la naturaleza femenina; para las liberales, una situación que podría permitir un tratamiento jurídico diferenciado. En la medida en que es un hecho crucial en la vida de la mayoría de mujeres, no ha de extrañar que el aborto y los métodos anticonceptivos hayan sido una de las reivindicaciones constantes de los colectivos feministas (críticamente Vega, 1988 , pp. 17ss.). La exigencia de autonomía reproductora se ha considerado como uno de los derechos de la mujer más importantes (Boetzkes, 1999, p.121).

Las técnicas de reproducción asistida han introducido un hecho diferencial en el proceso reproductor: permiten disociar sexualidad y reproducción y que las mujeres puedan llegar más tarde, e incluso solas, a la maternidad con posibilidades de éxito.

El movimiento feminista no podía ser indiferente frente a ellas (Wikler,1996. P.1080). Pero también en este punto hay, como ya hemos señalado, distintos planteamientos. Para mostrarlos nos servimos de un esquema cronológico, que toma como punto de referencia el estado de la cuestión en Norteamérica y cuya finalidad es simplemente marcar las 
tendencias predominantes, dado que en cada uno de estos momentos temporales pueden coexistir los distintos puntos de vista.

\subsection{LAS TECNICAS DE REPRODUCCION ASISTIDA \\ COMO MECANISMO DE LIBERACION}

En un primer momento, en los años setenta se consideraron positivas. Desde la perspectiva liberal se veían como un bien para las mujeres en la medida en que ofrecían nuevas posibilidades para controlar la reproducción. Firestone, en su libro La dialéctica feminista:: en defensa de la revolución feminista, denunciaba los aspectos opresivos de la maternidad, y creía que, si la reproducción pudiese tener lugar fuera del cuerpo femenino, las mujeres podrían abandonar el estado bárbaro del embarazo y alcanzar su liberación. En la medida en que se superasen los límites de la maternidad biológica se podría imponer una cultura andrógino en la que las mujeres, igual que los hombres, escogerían establecer o no relaciones de filiación. Desde esta perspectiva no se cuestionaban las técnicas en sí mismas como expresión del poder tecnológico controlado por los hombres, ni el sistema político y económico en el que dichas técnicas se desarrollaban, ya que la libertad reproductora significaba, sobre todo, verse liberadas de la reproducción (Birke, Himmelweit, Vines, 1992, página 15).

\subsection{LAS TECNICAS DE REPRODUCCION ASISTIDA}

COMO INSTRUMENTO DE LA CULTURA PATRIARCAL

En los años ochenta este optimismo tecnológico se truncó, en algunas mujeres, en un pesimismo radical que cuestionaba la capacidad de estas técnicas para favorecer la liberación femenina. En Estados Unidos surge un movimiento denominado FINRRAGE -Feminist International Network of Resistence to Reproductive and Genetic Engineering- cuyo objetivo es la denuncia y oposición a la ingeniería reproductora y genética. En un documento expresa las razones de su resistencia alegando 
que estas técnicas sirven básicamente de soporte al patriarcado en la medida en que: a) El poder reproductor de las mujeres queda bajo el control de los hombres (Ehrenreich, English, 1988); y b) Refuerzan el papel tradicional de madres que la sociedad ha asignado a las mujeres ( Stolcke, 1988, e Izquierdo, 1993.)

a) Dado que estas técnicas implican una instrumentalización de las mujeres, consideran que está justificado privar a las mujeres infértiles de su utilización. Entienden que cuando éstas se someten voluntariamente a esta explotación científica lo que hacen realmente es satisfacer los intereses del staff médico que se vale de su infertilidad para obtener beneficios profesionales y económicos. Su uso conlleva, también, que las mujeres pierdan el control de decisión sobre su propio cuerpo, culminando así el proceso que se inició cuando la profesión médica medicalizó la gestación y el parto. El poder de control de los maridos sobre las mujeres se transfiere a los

médicos. Esta medicalización tiene, a su vez, el inconveniente de que dificulta llevar a cabo investigaciones sociológicas sobre las causas sociales de la infertilidad.

b) Subrayan, además, que las decisiones voluntarias de las mujeres infértiles no son verdaderamente autónomas, pues se hallan mediatizadas por las medidas pronatalistas de la sociedad. Es la sociedad la que les crea la falsa conciencia de que ellas también quieren tener hijos. El deseo de tener un hijo no es un deseo nacido de sí mismas, sino que está construido socialmente, y a medida que las técnicas se perfeccionen les será más difícil a las mujeres poder resistirse a su utilización. Ponen en duda que el interés en tener un hijo biológico sea específicamente femenino. Creen, más bien, que se trata de un interés masculino pues para los hombres la paternidad es fundamentalmente la transmisión de los propios genes, mientras que para las mujeres la maternidad es básicamente el cuidado del niño (Shalev, 1992, p. 153).

También les preocupa que estas técnicas sirvan para favorecer prácticas eugenésicas. Estas prácticas no se identifican con los programas de 
perfeccionamiento racial, impulsados en los países occidentales a partir de los trabajos de Galton (1822-1911), que quedaron totalmente desprestigiados después de la Segunda Guerra Mundial. Ellas piensan, sobre todo, en lo que se denomina neoeugenesia que las parejas, en el ámbito estricto de la relación médico-paciente, presionen no sólo para tener un hijo, sino para que éste sea perfecto (Mele, 1998, página 147 y siguientes). Son contrarías a la selección del sexo del futuro hijo y a la experimentación con embriones porque creen que los femeninos serán sistemáticamente eliminados en favor de los masculinos (Puigpelat, 1997, pp. 104 ss.).

Este movimiento establece alianzas con los católicos conservadores, los movimientos ecologistas y los fundamentalistas cristianos, aunque no coinciden con éstos en algunos otros temas. Así, aunque las feministas se oponen a las nuevas técnicas y a la experimentación con embriones, no están en contra del aborto y de los métodos anticonceptivos. En estos casos no aceptan la actitud paternalista con las mujeres (Charlesworth, 1993 , pp. 92 ss.). Si la admiten, por ejemplo, en el caso de la maternidad subrogada. Consideran que en los contratos de subrogación las mujeres que consienten no son libres, sino que suelen estar presionadas por su situación socioeconómica o por el deseo de los hombres de tener un hijo biológico (Lima Añon, 1999, p. 139). Así como que con él no se abre la vía para la autonomía femenina, sino que ha de verse "como otra disposición del contrato sexual", como una nueva forma de acceso y uso de las mujeres por parte de los varones (Pateman, 1995, p.288).

En la medida en que la infertilidad va en aumento y/o muchas de las mujeres que ocupan posiciones sociales relevantes querrán evitar las posibles cargas del embarazo, las mujeres con pocos recursos económicos podrían conformar una casta reproductora dispuesta a ser explotada como lo son hoy las prostitutas. Sostienen, también, que dados los vínculos especiales que se establecen entre el hijo y la madre gestante no se puede obligar a la madre subrogada a cumplir el contrato de subrogación (Shalev, 1992, p.14) 


\subsection{LAS TÉCNICAS DE REPRODUCCIÓN ASISTIDA}

BAJO EL CONTROL DE LAS MUJERES.

En los últimos tiempos las posiciones feministas ante las técnicas de reproducción asistida son más matizadas. Aunque, en líneas generales, consideran que las nuevas tecnologías pueden ser peligrosas para las mujeres, creen que pueden servir para su liberación sí son las mujeres las que las controlan. Se oponen a la actitud paternalista del FINRRAGE y sostienen que las mujeres han de tomar sus propias decisiones confiando en que son capaces de resistir las presiones de los tecnócratas masculinos. Así la maternidad subrogada no se visualiza sólo en su aspecto negativo sino que se considera que puede ser una forma de evidenciar el valor económico del poder procreativo de las mujeres (Shalev, 1992, p. 167; Purdy, 1996, pp. 182 ss.).

Este cambio ha de reinterpretarse en relación con el propio movimiento feminista. En los últimos años se habla de feminismo posmoderno para aludir a un planteamiento que critica la modernidad y con ello la idea de una verdad única vinculada a la creencia en la objetividad, la universalidad y el esencialismo.

Las feministas posmodemas creen, como las radicales, que los conceptos "igualdad" y "mujer son construcciones sociales que han de ser revisadas. Pero no creen que la mejor forma de revisar el constructo patriarcal "mujer" sea construyendo otra categoría abstracta por parte de las mujeres. Para ellas son tan esencialistas el feminismo radical como el cultural (Restaino, Cavarero, 1999, p. 94 ss.).

Así, no creen que la perspectiva de la mujer, en abstracto, sea capaz de captar el impacto de la clase social, la raza, la etnia, la orientación sexual, las incapacidades y la cultura en la vida de las mujeres, sus experiencias y sus realidades. Abogan por un punto de vista feminista en el que la igualdad no signifique comparar la experiencia de las mujeres con la de los hombres, pero tampoco con la de un modelo de mujer universal y atemporal. Se trataría, más bien, de examinar las situaciones re- 
ales de las mujeres y no de definir la categoría 'mujer' pues toda definición es limitadora y, aunque no se explicite, se construye a partir de unas experiencias concretas. En este sentido las mujeres de color acusan al feminismo de que su punto de referencia son las mujeres blancas; las lesbianas, las mujeres heterosexuales; las trabajadoras, las de clase media, etc. La diversidad de intereses y experiencias de las propias mujeres hacen necesario, por tanto, que las soluciones no sean únicas sino diferenciadas.

Desde esta perspectiva no parece coherente criticar a la mujer estéril que utiliza estas técnicas alegando que tiene una falsa consciencia y que sólo ayuda a perpetuar los estereotipos de la cultura patriarcal y que, dado que el interés femenino en la maternidad no es el de la transmisión de genes, lo que debería hacer es adoptar a un niño desprotegido. Deben ser las propias mujeres estériles las competentes para decidir qué quieren y cuáles son sus proyectos de vida personales. No parece razonable que sean juzgadas por mujeres que no son estériles y/o por aquellas cuyo proyecto vital no es la maternidad biológica. También debe ser cada mujer, aunque no sea estéril, la que debe decidir si hace uso sola de las técnicas de reproducción asistida.

Sin embargo, el lema feminista 'lo que es personal es político' sigue teniendo vigencia. Con él quiere señalarse que los problemas que afectan básicamente a las mujeres -desigualdad en el mundo laboral, violencia familiar, acoso sexual, doble jornada, etc.-, no son problemas de carácter individual, sino que éstos están configurados por estructuras sociopolítícas que deben ser profundamente transformadas para conseguir la igualdad real entre personas de distinto sexo.

La construcción social de la contraposición "masculíno"/"femeníno" se ha podido mantener tanto tiempo porque construcciones alternativas más complejas, aunque eran mentalmente factibles, no lo podían ser en la vida real. Gracias a las innovaciones científicas y tecnológicas-desde los antíconceptivos a las lavadoras-, y la crítica social -que alerta del peligro de confundir lo que es con lo que debe o puede ser-, hoy esta- 
mos en condiciones de operar con modelos sociales más complejos que el de la división del trabajo y de los comportamientos "masculino" y "femenino". Los esfuerzos deben dirigirse, pues, a transformar los contextos sociales existentes para acabar con la situación de subordinación de la mujer. El problema no son las técnicas de reproducción asistida en sí mismas, sino el contexto social discriminador y competitivo en el que han surgido y se practican. 
BIRKE, L.; HIMMELWEIT, S.; VINES, G. (1992) El niño del mañana. Tecnologías reproducloras en los años 90. Barcelona: Ediciones PomaresCorredor.

CHARLESWORTH, M. (1993) Bioethics in a Liberal Society. Cambridge: Cambridge University Press.

CHORODOW, N. (1978) The Reproduction of Mothering: Psychoanalysis and the Sociology of Gender. Berkely: University of California.

ENGELS, F. (1970) El origen de la familia, la propiedad privada y el Estado. Madrid:

Fundamentos. Original de 1884.

EHRENREICH, B; ENGIJSH, D. (1988) Brujas, comadronas y enfermeras. Dolencias y transtornos. Barcelona: la Sal, edicions de les dones.

FACIO, A. (1992) Cuando el género suena, cambios trae. Caracas: GAIA, Centro de las mujeres.

FIRESTONE, S. (1974) La dialéctica feminista: en defensa de la revolución feminista. Barcelona: Kairós.

FRIEDAN, B. (1974) La mística de la feminidad. Madrid: Júcar.

GALTON, F. (1988) Herencia y Eugenesia. Madrid: Alianza Editorial.

GILLIGAN, C. (1985) La moral y la teoría, Psicología del desarrollo femenino. México: Fondo de Cultura Económica.

HARDING, S. (1982) "Is Gender a Variable in Conception of Rationality? A survey of Issues". Dialectica. Wol. 36, n. 23, páginas 225-242.

IZQUIERDO, M.J. (1993) "Ideología individualista y técnicas procreativas". Debate Feminista. Septiembre, páginas 67-75.

KOHLBERG, L. (1984) Essays on Moral Development San Francisco: Harper and Row Publishers.
KYMLICKA, W. (1 995) Fílosofia política contemporánea. Barcelona: Ariel.

LEMA AÑON, C. (1999) Reproducción, poder y derecho. Ensayo filosófico jurídico sobre las Técnicas de Reproducción Asistida. Madrid: Trotta. LLOYD; FREEMAN, M.D.A. (1994) Introduction to Jurisprudence, $6^{\mathrm{a}}$ ed.,. London: Swett \& Maxwell.

MACKINNON, K. (1987) Feminism Unmodified: Discourses on Ljfe and Law. Cambridge: Harvard University Press.

MELE, C. (1998) La bioetica al femminile. Milano: Vita e Pensiero.

MILLET, K. (1995) Política sexual. Madrid: Cátedra. PATEMAN, C. (1995) El contrato sexual. Barcelona: Antrophos

PUIGPELAT, F. (1997) "la selección de sexo: aspectos jurídicos y valoración crítica"'. Revista de Derecho y Genoma Humano. Vol. 6, páginas 93-109.

PURDY, L. (1996) Reproducíng Persons. Issues in Feminist Bioethics. Ithaca- Londres: Cbrnell University Press.

RESTAINO, F; CAVARERO, A. (1999) Le filosofle feministe. Torino: Paravia.

SHAJEV, C. (1992) Nascere per contratto. Milano: Giuffré Editore.

STOLCKE, V. (1988) "New Reproductive Technologies: the old Quest for Fatherhood"'., Reproductive and Genetic Engineering. Vol. $1, n^{\circ}$ 1, páginas 5-19.

URIA, P.; PINEDA, E.; OLJVÁN, M. (1985)

Polémicas feministas. Madrid: Editorial Revolución.

VECA, A. M. (1988) "Los «derechos reproductivos" en la sociedad postmoderna: iuna defensa o una amenaza contra el derecho a la vida?".

VIDAI, MARTÍNEZ, ]. (coord.) Derechos reproductivos y técnicas de reproducción asistida. Granada: Comares, páginas 1-52. 
Bibliografla

WIKLER, 1. (1996) -"Socicty's Response to the New Reproductive Technologies: The Feminist Perspective". WEISBERG, D. K. (ed.) Applications of Feminist Legal Theory to Women's Lives Sex, Volence, Work and Reproduction. Philadelphia: Temple University", páginas 1080-1091. 